\title{
Effectiveness of Boswellia and Boswellia extract for osteoarthritis patients: a systematic review and meta-analysis
}

\author{
Ganpeng Yu ${ }^{1 *} \mathbb{D}$, Wang Xiang ${ }^{2,3}$, Tianqing Zhang ${ }^{4,5}$, Liuting Zeng ${ }^{6}$, Kailin Yang ${ }^{7}$ and Jun $\mathrm{Li}^{1 *}$
}

\begin{abstract}
Background: Osteoarthritis $(\mathrm{OA})$ is the commonest form of inflammatory joint disease. Unfortunately, to date, there is no appropriate treatment for OA. Boswellia serrata was considered as a potent anti-inflammatory, anti-arthritic and analgesic agent that may be a drug for OA.

Methods: In this meta-analysis, data from randomized controlled trials were obtained to assess the effects of Boswellia or its extract versus placebo or western medicine in patients with OA. The primary outcomes included visual analogue score (VAS), WOMAC pain, WOMAC stiffness, WOMAC function and lequesne index.

Result: Seven trials involving 545 patients were included. Compared with the control group, Boswellia and its extract may relieve the pain IVAS: (WMD -8.33; 95\% Cl -11.19, - 5.46; $P<0.00001)$; WOMAC pain: (WMD -14.22; 95\% Cl $-22.34,-6.09 ; P=0.0006)$ ] and stiffness [WOMAC stiffness: (WMD $-10.04 ; 95 \% \mathrm{Cl}-15.86,-4.22 ; \mathrm{P}=0.0007)$ ], and improve the joint's function [WOMAC function: (WMD -10.75; 95\% Cl -15.06, $-6.43 ; P<0.00001)$; lequesne index: (WMD -2.27; 95\% Cl -3.08, - 1.45; $P<0.00001)]$.

Conclusion: Based on current evidence, Boswellia and its extract may be an effective and safe treatment option for patient with $\mathrm{OA}$, and the recommended duration of treatment with Boswellia and its extract is at least 4 weeks.
\end{abstract}

Keywords: Boswellia, Boswellia extract, Osteoarthritis, Systematic review, Meta-analysis

\section{Background}

Osteoarthritis (OA) is an inflammatory joint disease that mainly damages articular cartilage. It is characterized by the degradation of articular cartilage and involving the entire joint tissue, which eventually leads to joint degeneration, fibrosis, fracture, defect and damage to the entire articular surface [1-3]. Epidemiological studies show that there are currently 355 million people with arthritis worldwide, and arthritis has become the world's number one disabling disease. In China, as of 2015, there were 120 million people with arthritis in mainland

\footnotetext{
* Correspondence: yuganpeng.guke@hotmail.com; lijun.guke@hotmail.com 'The Department of Orthopaedics, People's Hospital of Ningxiang City, Ningxiang 410600, Hunan Province, China

Full list of author information is available at the end of the article
}

China, with an incidence rate of about $13 \%$, of which the number of people suffering from OA is the largest [4]. The management of patients with knee OA is mainly based on individualized and gradient treatment for the condition and severity of arthritis [5-7]. Among them, the drugs for OA pain are mainly non-steroidal antiinflammatory drugs (NSAID) and specific (COX-2) cyclooxygenase II inhibitors [8]. However, these drugs may be expensive or cause stomach bleeding, and cannot repair cartilage and treat subchondral damage [8-10]. Therefore, due to the high incidence of NSAID-related adverse events, there is an urgent need for a safer and effective alternative to OA.

Boswellic acid is the active ingredient in Boswellia serrata; it has shown significant pharmacological activity 
in the treatment of inflammatory diseases such as rheumatoid arthritis, chronic bronchitis, asthma and chronic inflammatory bowel diseases (ulcerative colitis and Crohn's disease) $[11,12]$. Current research showed that 3-O-Acetyl-11-keto-beta-boswellic acid (AKBA) is the one boswellic acid with strong pharmacological activity; for example, AKBA has a powerful inhibitory effect on 5-lipoxygenase (5-LOX) [13, 14]. Clinical studies have shown that Boswellia serrata extract not only has anti-inflammatory and anti-arthritis properties, but also improves pain and physical function [15-18]; in vitro experiments also show that Boswellia serrata extract can inhibit the expression of inflammatory factors such as adhesion molecules [19-23]. With regard to the safety of Boswellia serrata, studies showed that Boswellia serrata extract (such as 5-Loxin and Aflapin) does not have toxic side effects at higher doses [23-25]. These indicate that the active compound of Boswellia extract (AKBA) is safe based on current evidence [23, 25].

As potential anti-inflammatory drugs for $\mathrm{OA}$, the efficacy of Boswellia and Boswellia Extract have been reported in a lot of clinical trials [14-17, 24, 26]. Since 2003 [15], many trials have explored the feasibility of Boswellia and its extracts for the treatment of OA. In the meantime, the latest randomized controlled trials (RCTs) have assessed the benefits and adverse events of Boswellia and its extract for OA. To the best of our knowledge, this is the first systematic review and meta-analysis estimating the effectiveness and safety of Boswellia and its extracts for OA. Therefore, we hope that the results of this systematic review and meta-analysis will provide better evidence for the clinical application of Boswellia and its extract in the treatment of OA.

\section{Why it is important to do the review}

Boswellia and its extract have theoretical benefits for cultured cells in vitro and experimental animals [19, 21-23, $25,27]$; although several meta-analyses have widely analyzed the effect of herb or dietary supplements on OA [28, 29], to our knowledge, there is no systematic review and metaanalysis focused on assessing the efficacy of Boswellia and its extract on OA. For example, Liu et al. [28] conducted a systematic review about dietary supplements for patients with osteoarthritis; Of the studies it included, only three RCTs were about Boswellia and its extract. Meanwhile, its conclusions about Boswellia and its extract on OA failed to provide valuable reference information for clinical decision making. Another systematic review [29] only analyzed the RCTs before 2013. In 5 years, more RCTs about Boswellia and its extract on $\mathrm{OA}$ have been completed, which means that relevant conclusions need to be updated or confirmed. Therefore, this systematic review and meta-analysis focus on and summarizes available evidence from RCTs about the role of Boswellia and its extract in OA.

\section{Materials and methods Protocol}

Systematic reviews and meta-analysis are carried out strictly in accordance with the protocol (CRD42018086785) and the PRISMA-guidelines (see Supplementary Materials) [30].

\section{Search strategy and selection criteria}

Web of Science, the Chinese Science and Technology Periodical Database (VIP), Wan Fang Database (Chinese Ministry of Science \& Technology), EMBASE, Medline Complete, Chinese Biomedical Database (CBM), ClinicalTrials, the China National Knowledge Infrastructure Databases (CNKI), Pubmed, Cochrane Library (Until Issue 2, 2018) were searched with keywords "boswellic acid", "Boswellia", "Shallaki", "Salai", "aflapin", "5-loxin" and "osteoarthritis". The search period is from the establishment of the journal to January 2018.

\section{Selection criteria \\ Participants}

Human with specified diagnosis criteria of OA.

\section{Intervention methods}

Boswellia or its extract.

\section{Comparison methods}

Other treatments for OA, such as placebo or conventional medicine;

\section{Outcomes}

(1) Primary outcomes: visual analogue score (VAS), WOMAC pain, WOMAC stiffness, WOMAC function and lequesne index. (2) Secondary outcomes: WOMAC pain, WOMAC stiffness, WOMAC function at different points in time.

\section{Study design}

Randomized controlled trials (RCTs).

\section{Information retrieval and data extraction method}

Three researchers (Ganpeng Yu, Liuting Zeng and Kailin Yang) independently screened the literature based on protocol (CRD42018086785). The discrepancies between the three researchers would be resolved through discussion of all researchers. Literature retrieval is carried out according to the search strategy, the search strategy of Pubmed is shown in Table 1.

After literature retrieval, three researchers (Ganpeng $\mathrm{Yu}$, Liuting Zeng and Kailin Yang) extracted data from the included literature according to a pre-designed table (including author, year of publication, number of cases, inclusion and exclusion criteria of patients, duration of intervention, etc.). The discrepancies between the three researchers would be resolved through discussion of all 
Table 1 Search Strategy for Pubmed

\begin{tabular}{ll}
\hline Database & Search Strategy \\
\hline Pubmed & (boswellic acid OR Boswellia OR Boswellia sacra OR Boswellia \\
& serrata OR Boswellia carteri OR Boswellia carterii OR Shallaki \\
& OR Salai OR aflapin OR 5-loxin) \\
& AND \\
& (Osteoarthritis OR Osteoarthritides OR Osteoarthrosis OR \\
& Osteoarthroses OR Arthritis, Degenerative OR Arthritides, \\
& Degenerative OR Degenerative Arthritides OR Degenerative \\
& Arthritis OR Osteoarthrosis Deformans) \\
& AND \\
& (randomized controlled trial [pt] OR controlled clinical trial \\
& [pt] OR placebo [tiab] OR drug therapy [sh] OR trial [tiab] OR \\
& groups [tiab] OR clinical trials as topic [mesh: noexp] OR \\
& Clinical Trial OR random* [tiab] OR random allocation [mh] \\
& OR single-blind method [mh] OR double-blind method [mh] \\
& OR cross-over studies) \\
& NOT \\
& (animals [mh] NOT humans [mh]) \\
&
\end{tabular}

researchers. The missing data in the literature would be obtained by contacting the author. If the author cannot be contacted, it would be estimated by the method provided by Cochrane Handbook 5.1.0 [31].

\section{Literature quality evaluation methods}

The Cochrane collaboration's tool for assessing risk of bias provided by Cochrane Handbook 5.1.0 was used to evaluate the quality of the RCTs [32]. The evaluation content includes random sequence generation, allocation result concealment, blind method, incomplete result data, selective report and other biases. Four researchers (Ganpeng Yu, Wang Xiang, Tianqing Zhang, Liuting Zeng and Kailin Yang) independently assessed the quality of the literature. The discrepancies between the three researchers would be resolved through discussion of all researchers.

\section{Statistical analysis}

The RevMan5.3 software provided by the Cochrane collaboration network was used for system evaluation and meta-analysis. Enumeration data is represented by risk ratio (RR) and 95\% confidence interval (CI), and measurement data is represented by mean deviation (MD) and CI. The heterogeneity between the results of the studies was tested by $\mathrm{X}^{2}$. If the heterogeneity of the study is low $\left(\mathrm{P}>0.10, \mathrm{I}^{2}<50 \%\right)$, the fixed effect model is used for analysis; otherwise $(\mathrm{P}<0.10, \mathrm{I} 2>50 \%)$, the source of heterogeneity is analyzed first and then subgroup analysis or random effect model is adopted.

\section{Results}

\section{Results of the search}

The total records identified through database searching and other sources were 513. Four hundred ninety-seven (497) were excluded based on the title and abstract and 16 for more detailed evaluation. After that, 7 studies were included [24, 26, 33-37], while 9 studies were excluded [15-18, 38-42] according to the inclusion criteria (Fig. 1). The 9 studies were Kimmatkar 2003 [15], Chopra 2004 [38], Shah 2010 [17], Chopra 2013 [39], Perera 2014 [16], Belcaro 2015 [40], Bolognesi 2016 [41], Gupta 2011 [18], Badria 2002 [42].

\section{Description of included trials}

A total of 7 RCTs with 545 participants were included. Sengupta's RCTs consist of 2 trial groups and 1 control group $[24,26]$. According to the method of Cochrane Handbook 5.1.0, the control group was divided into two groups, matching the two trial groups (Sengupta 2008a and Sengupta 2008b; Sengupta 2010a and Sengupta 2010b) [31]. The characteristics of the RCTs were shown in Tables 2 and 3.

\section{Risk of Bias in included studies}

The summary and graph of risk of bias ware shown in Fig. 2.

\section{Sequence generation}

Among the 7 included RCTs, three studies [35-37] adopted unclear randomization procedures, we therefore rated it as having an unclear risk of bias. The other RCTs described their randomization procedures: Sengupta 2010 [24], Sengupta 2008 [26] and Vishal 2011 [33] utilized the computer-generated randomization scheme, while Haroyan 2018 [34] used the treatment randomization code to draw randomization. Thus, these RCTs were thought to have low risks of bias.

\section{Allocation concealment}

Sengupta 2010 [24], Sengupta 2008 [26], Vishal 2011 [33] and Haroyan 2018 [34] described that the appearance, smell and color of drugs preparations were similar and organoleptically indistinguishable, which is an acceptable method of allocation concealment. Hence, they were rated as having low risks of bias. Karimifar 2017 [35], Notarnicola 2016 [36] and Notarnicola 2011 [37] did not describe an acceptable method of allocation concealment; therefore, they were rated as having an unclear risk of bias.

\section{Blinding}

For blinding of participants and personnel, although all RCTs claim to use blinding, only Haroyan 2018 [34], Notarnicola 2016 [36] and Notarnicola 2011 [37] described the implementation process of blinding. Thus, we gave a low risk of bias for them. The other RCTs were rated as having an unclear risk of bias for they did not describe the blind implementation process.

For blinding of outcome assessment, the statisticians in Sengupta 2010 [24], Sengupta 2008 [26] and Vishal 


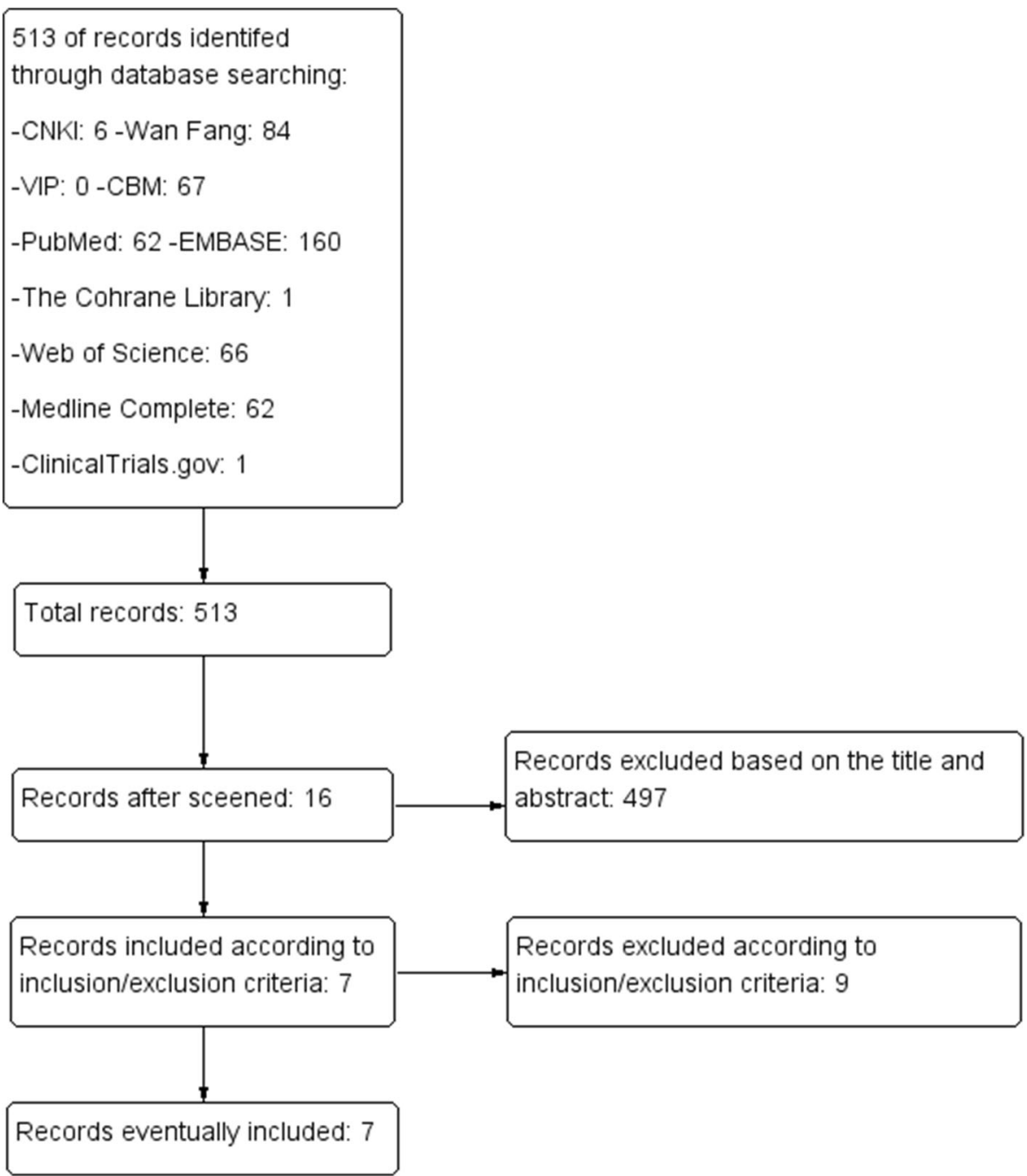

Fig. 1 Flow diagram of searching and article selection

2011 [33] wasn't blinded, hence, they were rated as having a high risk of bias. Haroyan 2018 [34], Notarnicola 2016 [36] and Notarnicola 2011 [37] described the implementation process of blinding, hence, we gave a low risk of bias for them. Karimifar 2017 [35] were rated as having an unclear risk of bias for they did not describe the blind implementation process.

\section{Incomplete outcome data}

The missing outcome data of all RCTs balanced in numbers across intervention groups with similar reasons for missing data across groups. We gave them low risks of bias.

\section{Selective reporting}

One RCT (Vishal 2011 [33]) failed to provide all outcomes mentioned in its protocols, thus we thought its risk of bias was high. The other RCTs provided their protocols, and all of the study's pre-specified outcomes that are of interest in the review had been reported in the pre-specified way; their risks of bias were low.

\section{Other potential bias}

In the RCTs of Sengupta 2010 [24], Sengupta 2008 [26] and Vishal 2011 [33], their protocols noted three primary outcome parameters, which means that when $p=0.05 / 3=0.017$, the difference is significant. Strictly speaking, the statistics of this study were not carried out correctly. Hence, their risks of bias were high. Similarly, in Haroyan 2018 [34]'s RCT, the difference is significant when $\mathrm{p}=0.05 / 2=0.025$. Its risk of bias was also high. Other sources of bias were not observed in other RCTs; therefore, the risks of other bias of them were low. 


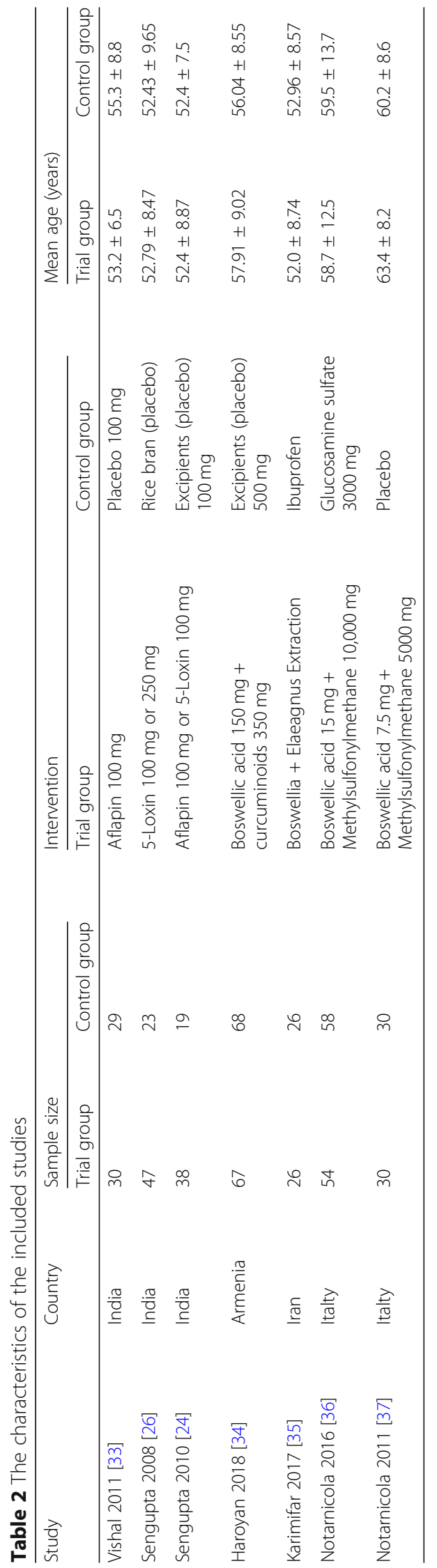


Table 3 The characteristics of the included studies

\begin{tabular}{|c|c|c|}
\hline Study & Inclusion criteria & Exclusion criteria \\
\hline $\begin{array}{l}\text { Vishal } \\
2011 \text { [33] }\end{array}$ & $\begin{array}{l}\text { 1. Participants must understand risks and } \\
\text { benefits of the protocol and able to give } \\
\text { informed consent } \\
\text { 2. Male and female subjects of } \\
\text { 40-80 years of age } \\
\text { 3. Females of child bearing potential } \\
\text { must agree to use an approved form of } \\
\text { birth control and have a negative } \\
\text { pregnancy test result } \\
\text { 4. Unilateral or bilateral OA of the knee } \\
\text { for more than } 3 \text { months } \\
\text { 5. Visual Analogue Scale (VAS) score } \\
\text { during the most painful knee movement } \\
\text { between } 40 \text { and } 70 \text { mm after } 7 \text { day } \\
\text { withdrawal of usual medication } \\
\text { 6. Lequesne's Functional Index (LFI) score } \\
\text { greater than } 7 \text { points after } 7 \text { days of } \\
\text { withdrawal of usual medication } \\
\text { 7. Ability to walk } \\
\text { 8. Availability for the duration of the } \\
\text { entire study period }\end{array}$ & $\begin{array}{l}\text { 1. History of underlying inflammatory } \\
\text { arthropathy or severe rheumatoid arthritis } \\
\text { (RA) } \\
\text { 2. Hyperuricemia } \\
\text { (greater than } 440 \text { umol/L) and/or } \\
\text { past history of gout } \\
\text { 3. Recent injury in the area affected by } \\
\text { OA of the knee (past } 4 \text { months) and } \\
\text { expectation of surgery in the next } \\
4 \text { months } \\
\text { 4. Intra-articular corticosteroid injections } \\
\text { within the last } 3 \text { months } \\
\text { 5. Hypersensitivity to non-steroidal } \\
\text { anti-inflammatory drugs (NSAIDs), } \\
\text { abnormal liver or kidney function tests, } \\
\text { history of peptic } \\
\text { ulceration and upper gastrointestinal (Gl) } \\
\text { haemorrhage, congestive heart failure, } \\
\text { hypertension, hyperkalemia } \\
6 . \text { Major abnormal findings on complete } \\
\text { blood count, history of coagulopathies, } \\
\text { haematological or neurological disorders } \\
\text { 7. High alcohol intake (greater than } 2 \\
\text { standard drinks per day) } \\
\text { 8. Pregnant, breastfeeding or planning to } \\
\text { become pregnant during the study } \\
\text { 9. Use of concomitant prohibited } \\
\text { medication other than ibuprofen } \\
\text { 10. Obesity: body mass index (BMI) more } \\
\text { than } 30 \text { kg/m^ } 2\end{array}$ \\
\hline
\end{tabular}

Haroyan Patients with a diagnosis of degenerative 2018 [34] hypertrophic osteoarthritis of the knee (M17, according to International Classification of Diseases (ICD-10) of bone joints, verified by radiography (Grade 1-3 by Kellgren-Lawrence radiographic grades).

Karimifar 1. age of 40 to 80 years

2017 [35] 2. knee osteoarthritis in at least one knee

for at least 6 months based on ACR

(American College of Rheumatology) diagnostic criteria

3. pain score $>4$ based on VAS (visual analog scale)

4. LPFI (Lequesne Pain and Function

Index) $>7$

5. serum CRP (C-reactive protein) $<$

$10 \mathrm{mg} / \mathrm{dl}$ and ESR (erythrocyte

sedimentation rate) $<20 \mathrm{mg} / \mathrm{dL}$, (6)

grade 2 or 3 of KellgrenLawrence scale

in knee radiography obtained within the last 6 months

7. free of liver, renal, or cardiac dysfunction 8. no use of intra-articular glucocorticoids or hyaluronic acid preparations within the last 3 months

9. no use of systemic glucocorticoids within the last 3 months

10. free of all other bone and joint

1. subjects with inflammatory and any secondary arthritis

2. moderate and severe synovitis

(grades 2 and 3 ) tear of meniscus

3. chronic diseases of the kidneys, liver,

gastrointestinal, cardiovascular, endocrine and nervous systems

4. allergic anamnesis and drug intolerance

5. pregnant or nursing

6. history of substance abuse

7. subjects taking non-steroidal

anti-inflammatory drugs and analgesics

within 2 weeks prior to the

study

8. subjects taking glucosamine sulfate,

chondroitin sulfate, intra-articular

hyaluronate, systemic or

intra-articular glucocorticoids within

3 months prior to the study

1. irregular use of capsules (less than $80 \%$ of total capsules)

2. no use of capsules for at least 3 days

$\begin{array}{ll}\text { Relevant outcomes } & \text { Duration } \\ \text { VAS, WOMAC pain subscale, } & 4 \text { weeks } \\ \text { WOMAC stiffness subscale, } & \\ \text { WOMAC function subscale, } & \\ \text { Lequesne Index, adverse events } & \end{array}$

VAS, WOMAC pain subscale, WOMAC stiffness subscale,

12 weeks WOMAC function subscale, Lequesne Index, MMP-3, adverse events

VAS, WOMAC pain subscale, WOMAC stiffness subscale, WOMAC function subscale, Lequesne Index, adverse events

12 weeks

WOMAC pain subscale, WOMAC

12 weeks stiffness subscale, WOMAC

function subscale, adverse events

VAS, Lequesne Index, adverse

4 weeks events 
Table 3 The characteristics of the included studies (Continued)

\begin{tabular}{|c|c|c|c|c|}
\hline Study & Inclusion criteria & Exclusion criteria & Relevant outcomes & Duration \\
\hline & $\begin{array}{l}\text { disorders including rheumatoid arthritis } \\
\text { and gout } \\
\text { 11. free of peptic ulcer disease } \\
\text { 12. no knee arthroscopic procedure within } \\
\text { the last } 3 \text { months } \\
\text { 13. not being pregnant or lactating } \\
\text { (for women). }\end{array}$ & & & \\
\hline $\begin{array}{l}\text { Notarnicola } \\
2016 \text { [36] }\end{array}$ & $\begin{array}{l}\text { 1. a diagnosis of OA of the knee according } \\
\text { to the criteria of the American College of } \\
\text { Rheumatology } \\
\text { 2. grade } 3 \text { Kellgren and Lawrence } \\
\text { radiographic staging, } 16 \text { in which the } \\
\text { severity of the arthritis is assessed on a scale } \\
\text { in the range of } 0 \text { - } 4 \text {, hypothesizing a } \\
\text { sequential evolution from the manifestation } \\
\text { of osteophytes through a reduction in the } \\
\text { width of the joint space, to subchondral } \\
\text { sclerosis and finally the formation of cysts } \\
\text { 3. frequent joint pain (several days a week) } \\
\text { for at least } 6 \text { months before recruitment } \\
4 \text {. pain in the knee, scored at least } 4 \mathrm{~cm} \text { on } \\
\text { a } 10 \text { centimetric visual analogic scale (VAS) } \\
\text { (from moderate to severe pain), where } 0 \\
\text { means no pain and } 10 \text { is the worst pain } \\
\text { possible } \\
5 . \text { a score of }>2 \text { on the Lequesne pain- } \\
\text { function index (LI).18 The LI is an OA-specific } \\
\text { validated questionnaire that poses a series } \\
\text { of questions about pain in the knee (five } \\
\text { questions on a scale from } 0 \text { to } 2 \text {, where } 0 \\
\text { indicates no pain and } 2 \text { intense pain), } \\
\text { functional limitation (four questions, using } \\
\text { the same scale), and maximum walking } \\
\text { distance (one question, with a score from } \\
0 \text { to } 6 \text {, where } 0 \text { indicates the ability to walk } \\
\text { for an unlimited distance and } 6 \text {, the inability } \\
\text { to cover } 100 \text { m). The maximum worst final } \\
\text { score is } 24\end{array}$ & $\begin{array}{l}\text { 1. previous surgery of the affected knee } \\
\text { 2. disease processes such as rheumatoid } \\
\text { arthritis, autoimmune diseases, systemic } \\
\text { diseases, and tumors } \\
\text { 3. severe obesity (BMI > } 40 \mathrm{~kg} / \mathrm{m} 2 \text { ) } \\
\text { 4. meniscal or ligament injuries } \\
\text { 5. allergy to shellfish } \\
\text { 6. altered blood chemistry and kidney, } \\
\text { liver, and metabolic (diabetes mellitus) } \\
\text { function } \\
\text { 7. intra-articular hyaluronic acid/cortisone } \\
\text { infiltrations to the affected knee within } \\
3 \text { months before the start of the study } \\
\text { 8. systemic cortisone treatment taken } \\
\text { within } 3 \text { months before the start of the } \\
\text { study; } \\
\text { 9.supplements (glucosamine, chondroitin } \\
\text { sulfate, bromeline, etc.) taken within } \\
3 \text { months before the start of the study } \\
\text { (patients were also informed that they } \\
\text { were not to be taken for the following } \\
6 \text { months) }\end{array}$ & VAS, Lequesne Index & 24 weeks \\
\hline $\begin{array}{l}\text { Notarnicola } \\
2011[37]\end{array}$ & $\begin{array}{l}\text { 1. men and women }>45 \text { and }<85 \text { years of } \\
\text { age; } \\
\text { 2. a diagnosis of OA of the knee according } \\
\text { to the criteria of the American College of } \\
\text { Rheumatology } \\
\text { 3. grade } 3 \text { Kellgren and Lawrence } \\
\text { radiographic staging, } 13 \text { in which the } \\
\text { severity of the arthritis is assessed on a scale } \\
\text { from } 0 \text { to } 4 \text {, hypothesizing a sequential } \\
\text { evolution from the manifestation of } \\
\text { osteophytes through a reduction in the } \\
\text { width of the joint space, to subchondral } \\
\text { sclerosis and fnally the formation of cysts; } \\
\text { 4. frequent joint pain (several days a week) } \\
\text { for at least } 6 \text { months before recruitment; } \\
\text { 5. pain in the knee, scored at least } 2 \text { cm on } \\
\text { a } 10 \text { centimetric visual analogic scale (VAS), } \\
\text { where } 0 \text { means no pain and } 10 \text { is the worst } \\
\text { pain possible; } \\
6 \text {. a score of }>2 \text { on the Lequesne pain- } \\
\text { function index (LI). } 14 \text { The LI is a disease- } \\
\text { specific validated } \\
\text { questionnaire that poses a series of } \\
\text { questions about pain in the knee (five } \\
\text { questions on a scale from } 0 \text { to } 2 \text {, where } \\
0 \text { indicates no pain and } 2 \text { intense pain), } \\
\text { functional limitation (four questions, using } \\
\text { the same scale) and maximum walking } \\
\text { distance (one question, with a score from } \\
0 \text { to } 6 \text {, where } 0 \text { indicates the ability to walk } \\
\text { for an unlimited distance and } 6 \text {, the inability } \\
\text { to cover } 100 \text { m). The maximim worst fnal } \\
\text { score was } 24 \text {. }\end{array}$ & $\begin{array}{l}\text { 1. previous surgery of the affected knee; } \\
\text { 2. disease processes such as rheumatoid } \\
\text { arthritis, autoimmune diseases, systemic } \\
\text { diseases, and tumors; } \\
\text { 3. obesity (BMI > } 30 \mathrm{~kg} / \mathrm{m} 2) \text {; } \\
\text { 4. altered blood chemistry and kidney, } \\
\text { liver, and metabolic (diabetes mellitus) } \\
\text { function; } \\
\text { 5. intra-articular hyaluronic acid/cortisone } \\
\text { infiltrations to the affected knee within } \\
3 \text { months before the start of the study; } \\
6 \text {. systemic cortisone treatment taken } \\
\text { within } 3 \text { months before the start of the } \\
\text { study; } \\
\text { 7. supplements (glucosamine, chondroitin } \\
\text { sulfate, bromeline, etc) taken within } \\
3 \text { months before the start of the study } \\
\text { (patients were also informed that they } \\
\text { were not to be taken for the following } \\
6 \text { months). }\end{array}$ & $\begin{array}{l}\text { VAS, Lequesne Index, } \\
\text { adverse events }\end{array}$ & 24 weeks \\
\hline
\end{tabular}



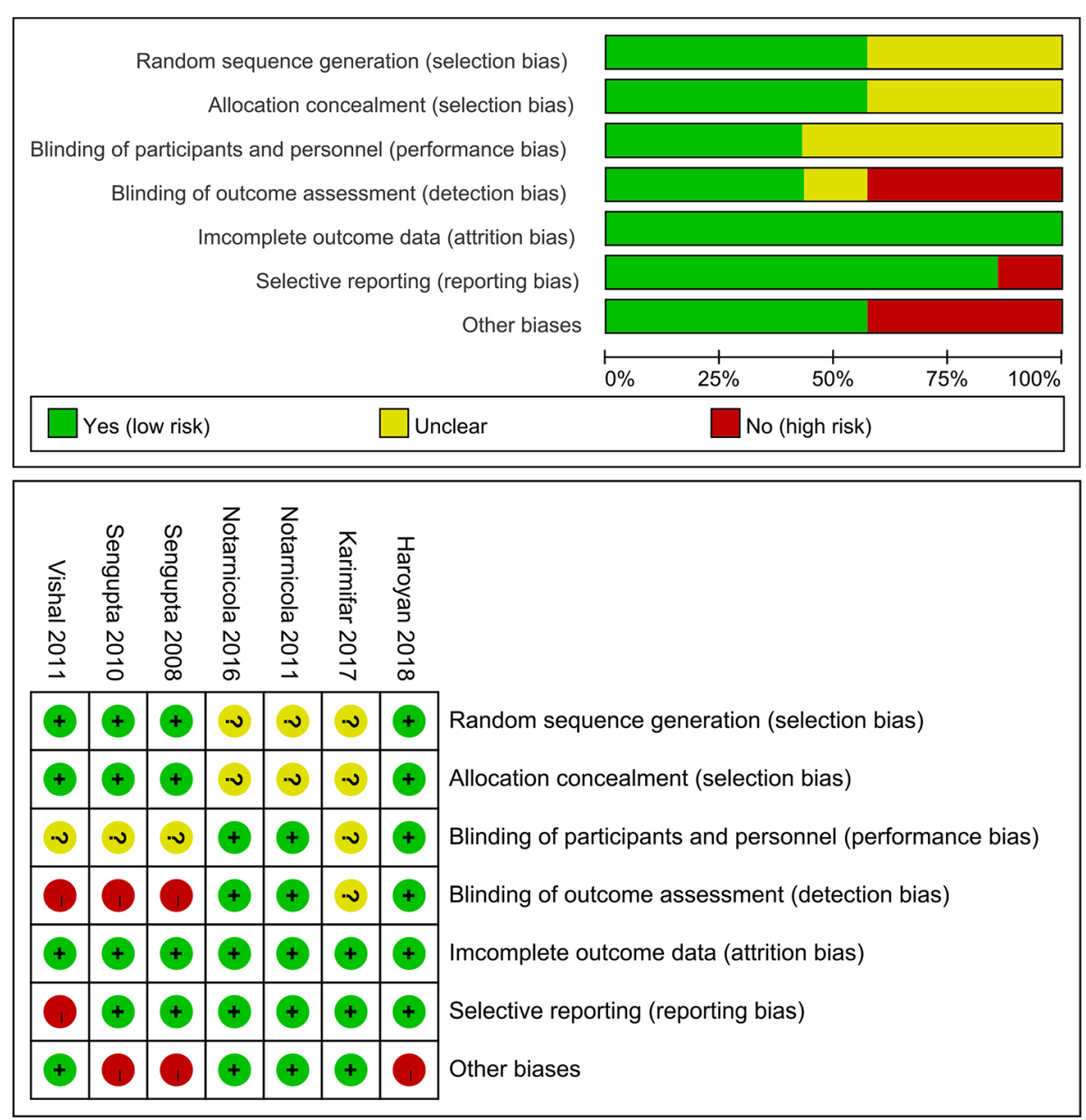

Fig. 2 The risk of bias

\section{Primary outcomes}

\section{Visual analogue score}

Six RCTs [24, 26, 33, 35-37] reported the changes of the visual analogue score (VAS) at the end of treatment. Due to the high heterogeneity $\left(\mathrm{Tau}^{2}=10.85, \mathrm{I}^{2}=94 \%, P<\right.$ $0.00001)$, we used random effect model. In this index, it can be found that in improving VAS, Boswellia is better (WMD -8.33; 95\% CI -11.19, - 5.46; P<0.00001). (Fig. 3).

\section{WOMAC}

Four RCTs [24, 26-, 34-35] reported the changes of WOMAC pain. Due to the high heterogeneity $\left(\mathrm{Tau}^{2}=\right.$

\begin{tabular}{|c|c|c|c|c|c|c|c|c|c|}
\hline \multirow[b]{2}{*}{ Study or Subgroup } & \multicolumn{3}{|c|}{ Boswellia } & \multicolumn{2}{|c|}{ Control } & \multirow[b]{2}{*}{ Total } & \multirow[b]{2}{*}{ Weight } & \multirow{2}{*}{$\begin{array}{l}\text { Mean Difference } \\
\text { IV. Random, } 95 \% \mathrm{Cl}\end{array}$} & \multirow{2}{*}{$\begin{array}{l}\text { Mean Difference } \\
\text { IV. Random, } 95 \% \mathrm{Cl}\end{array}$} \\
\hline & Mean & SD & Total & Mean & SD & & & & \\
\hline Vishal 2011 & -23.5 & 10.31 & 30 & -8.3 & 9.6 & 29 & $12.2 \%$ & $-15.20[-20.28,-10.12]$ & $\rightarrow$ \\
\hline Sengupta 2008a & -35.68 & 8.04 & 24 & -15.12 & 14.42 & 11 & $6.6 \%$ & $-20.56[-29.67,-11.45]$ & \\
\hline Sengupta 2008b & -41.4 & 8.31 & 23 & -15.12 & 14.42 & 12 & $6.9 \%$ & $-26.28[-35.12,-17.44]$ & \\
\hline Sengupta $2010 a$ & -22 & 14.45 & 19 & -9.4 & 8.05 & 9 & $7.4 \%$ & $-12.60[-20.96,-4.24]$ & \\
\hline Sengupta 2010b & -27.5 & 10.71 & 19 & -9.4 & 8.05 & 10 & $9.2 \%$ & $-18.10[-25.03,-11.17]$ & \\
\hline Karimifar 2017 & -2.19 & 1.74 & 26 & -1.71 & 1.5 & 26 & $19.4 \%$ & $-0.48[-1.36,0.40]$ & 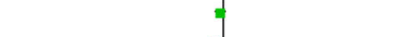 \\
\hline Notarnicola 2016 & -3.1 & 2.26 & 54 & -1.5 & 1.71 & 58 & $19.5 \%$ & $-1.60[-2.35,-0.85]$ & $\square$ \\
\hline Notarnicola 2011 & -4.8 & 2.18 & 30 & -3.1 & 2.71 & 30 & $19.0 \%$ & $-1.70[-2.94,-0.46]$ & - \\
\hline Total $(95 \% \mathrm{Cl})$ & & & 225 & & & 185 & $100.0 \%$ & $-8.33[-11.19,-5.46]$ & \\
\hline \multicolumn{9}{|c|}{$\begin{array}{l}\text { Heterogeneity: } \mathrm{Tau}^{2}=10.85 ; \mathrm{Chi}^{2}=108.69, \mathrm{df} \\
\text { Test for overall effect: } \mathrm{Z}=5.69(\mathrm{P}<0.00001)\end{array}$} & $\begin{array}{ccccc}-20 & -10 & 0 & 10 & 20 \\
\text { Favours [Boswellia] } & \text { Favours [Control] }\end{array}$ \\
\hline
\end{tabular}


94.69, $\left.\mathrm{I}^{2}=99 \%, P<0.00001\right)$, we used random effect model. According to the result, compared with the control group, Boswellia is better in improving WOMAC pain (WMD -14.22; 95\% CI -22.34, - 6.09; $\mathrm{P}=0$. 0006). (Fig. 4).

Four RCTs [24, 26, 33, 34] reported the changes of WOMAC stiffness. Due to the high heterogeneity $\left(\mathrm{Tau}^{2}=44.40, \mathrm{I}^{2}=97 \%, P<0.00001\right)$, we used random effect model. According to the result, compared with the control group, Boswellia is better in improving WOMAC stiffness (WMD -10.04; 95\% CI -15.86, - 4.22; $\mathrm{P}=$ 0. 0007). (Fig. 5).

Four RCTs [24, 26, 33, 34] reported the changes of WOMAC function. Due to the high heterogeneity $\left(\mathrm{Tau}^{2}=23.03, \mathrm{I}^{2}=93 \%, P<0.00001\right)$, we used random effect model. According to the result, compared with the control group, Boswellia is better in improving WOMAC function (WMD -10.75; 95\% CI -15.06, - 6.43; $P<0.00001$ ). (Fig. 6).

\section{Lequesne index}

Six RCTs [24, 26, 33, 35-37] reported the changes of lequesne index. Due to the high heterogeneity $\left(\mathrm{Tau}^{2}=\right.$ $0.55, \mathrm{I}^{2}=47 \%, \mathrm{P}=0.07$ ), we used random effect model. According to the result, compared with the control group, Boswellia is better in improving Lequesne Index (WMD -2.27; 95\% CI -3.08, - 1.45; P<0.00001). (Fig. 7).

\section{Secondary outcomes}

\section{Pain}

Several RCTs reported Pain index (VAS and/or WOMAC pain) at week 4, 8, 12. The details of them were shown in Table 4 and Figure S1 S6 (see Supplementary Materials).

\section{Stiffness}

Several RCTs reported Stiffness index (WOMAC stiffness) at week 4, 8, 12. The details of them were shown in Table 5 and Figure S7 S9 (see Supplementary Materials).

\section{Function}

Several RCTs reported Function index (WOMAC function) at week $4,8,12$. The details of them were shown in Table 6 and Figure S10 S12 (see Supplementary Materials).

\section{Adverse events}

Five studies [24, 33-35, 37] reported AEs. Three of them were excluded because they reported no events in both arms. According to the results, there is also not strong evidence that which one is safer because there was no statistical difference (RR 0.63; 95\% CI 0.22, $1.83 ; \mathrm{P}=$ 0.39) (Fig. 8).

\section{Discussions}

This systematic review and meta-analysis including 7 RCTs analyzes the effectiveness and safety of Boswellia and its extract for OA. Compared with the control group, Boswellia and its extract may relieve the pain (VAS and WOMAC pain) and stiffness (WOMAC stiffness), and improve the joint's function (WOMAC function and lequesne index). In particular, since the doses of Boswellia and its extract reported in RCTs used for secondary outcomes analysis are 100-250 mg, based on the current evidence, pain, stiffness and joints' function start to improve after 4 weeks of continuous Boswellia and its extract (at least 100-250 mg) intervention. While this finding seems promising, it should be interpreted with caution mainly due to the unclear risk of bias for selection bias (random sequence generation, allocation concealment) and attrition bias (incomplete outcome data), the high risk of bias for reporting bias (selective reporting), and the small number of participants.

Five studies [24, 33-35, 37] reported AEs. Three of them were excluded because they reported no events in both arms. According to the results, there is also not strong evidence that which one is safer because there was no statistical difference. However, safety studies conducted according to OECD guidelines and extensive acute and dose-dependent subchronic safety experiments on rats demonstrate that Boswellia and its extract does not exhibit toxic manifestations [23, 25], which

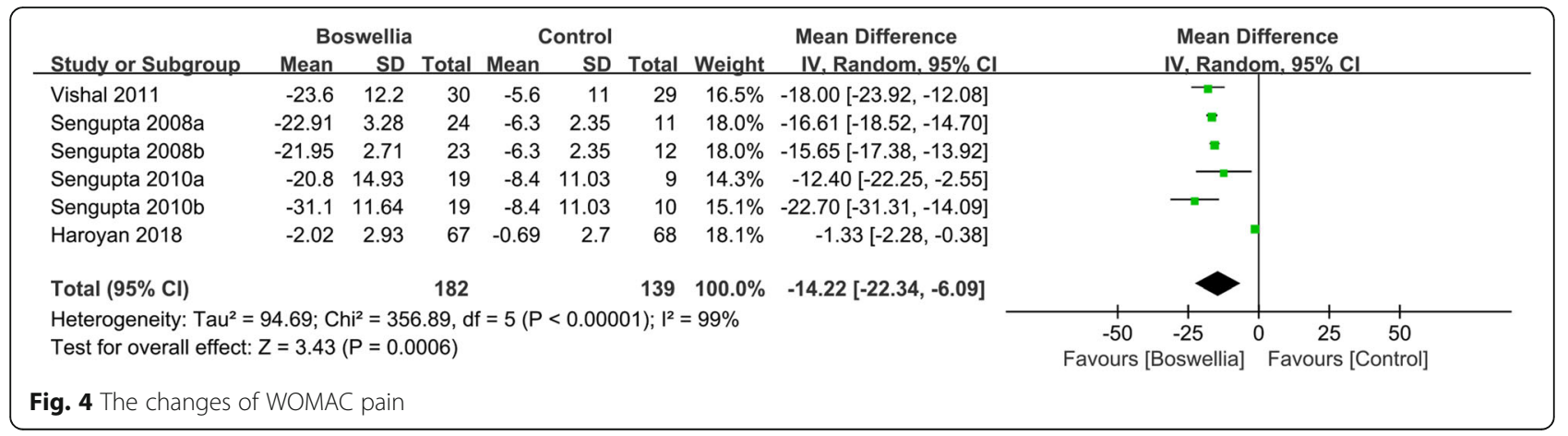




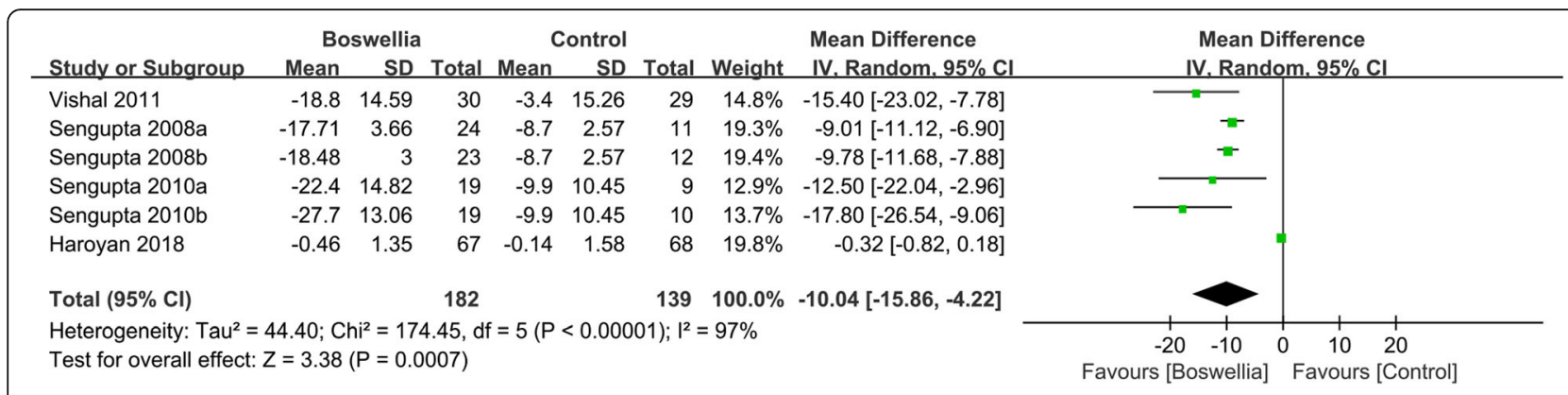

Fig. 5 The changes of WOMAC stiffness

means Boswellia and its extract might be a safety treatment option. But the absence of information on AEs does not mean that the intervention is safe [43]. Thus, although based on current evidences, we consider that Boswellia and its extract is a relatively safe treatment, we cannot assure it. Future clinical trials are required to re- supplements on OA $[28,29]$, as far as we know, this systematic review and meta-analysis is the first one that focused on evaluating the efficacy and safety of Boswellia and its extract for patients with OA. Compared with similar previous works $[28,29]$, we included more RCTs (including [33-36]) about Boswellia and its extract; thus,

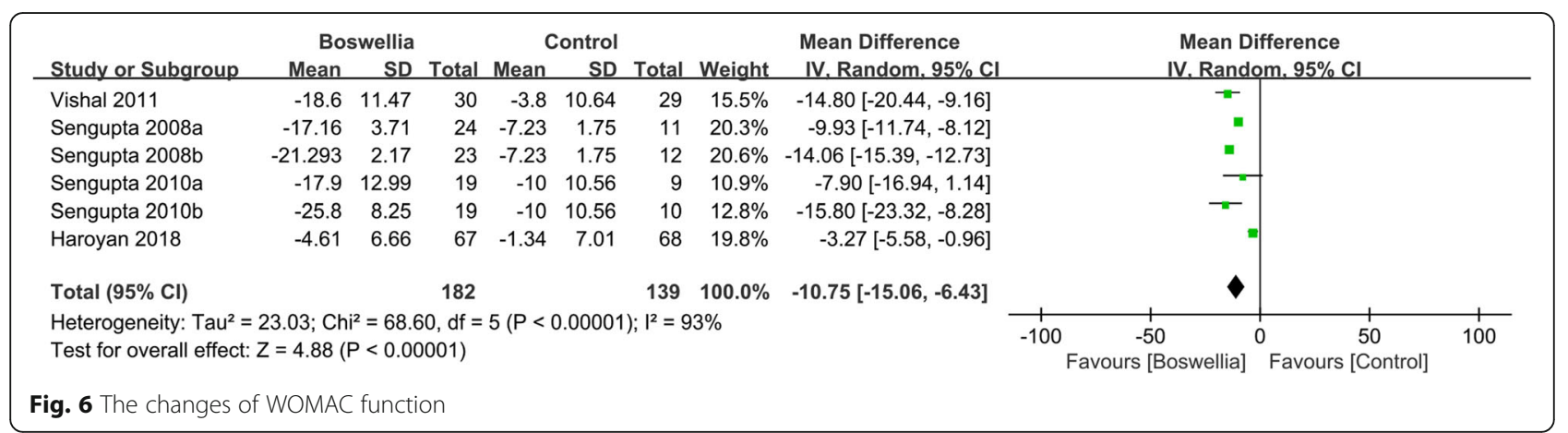

port AEs with more explanations [44]. Thus, although based on current evidences, we consider that Boswellia and its extract is a relatively safe treatment, we cannot assure it. Future clinical trials are required to report AEs with more explanations [45].

Although there were several meta-analyses that have been widely analyzed the effect of herb or dietary our conclusions were more accurate and reliable. In particular, compared with the work of Cameron et al. [29], we not only verified some outcomes (such as WOMAC) but also provide the recommended duration and dosage of Boswellia and its extract and so on. However, there are still some deficiencies in this study. For example, the risk of bias of some RCTs are high; the number of RCTs

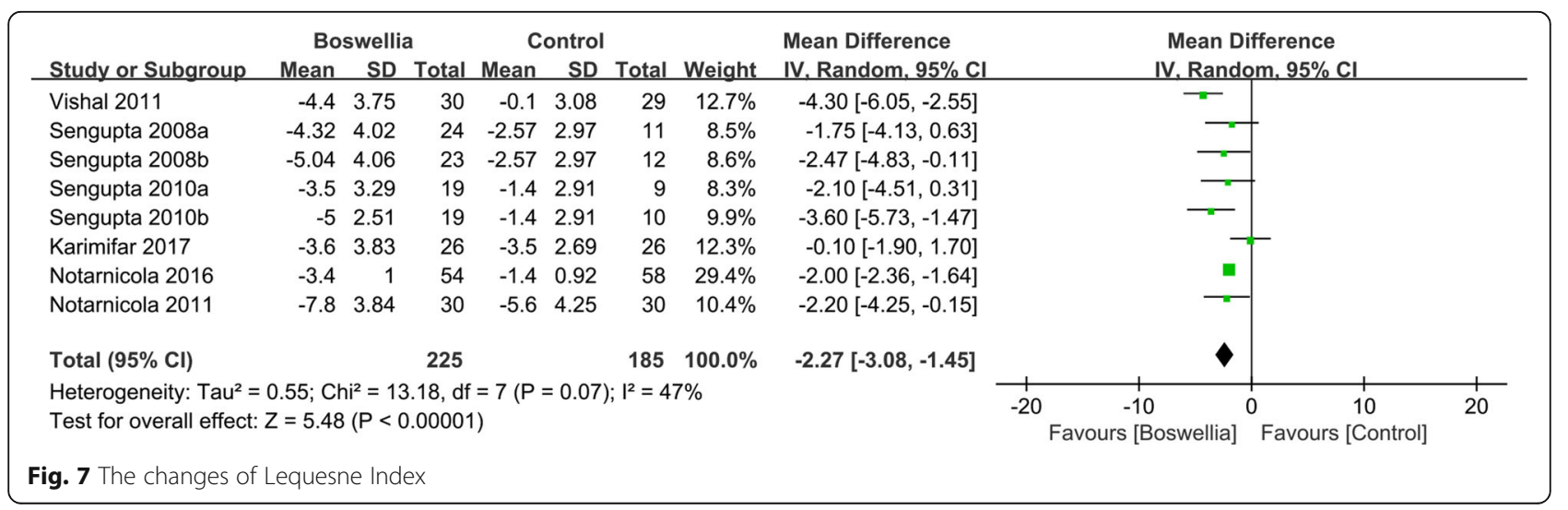




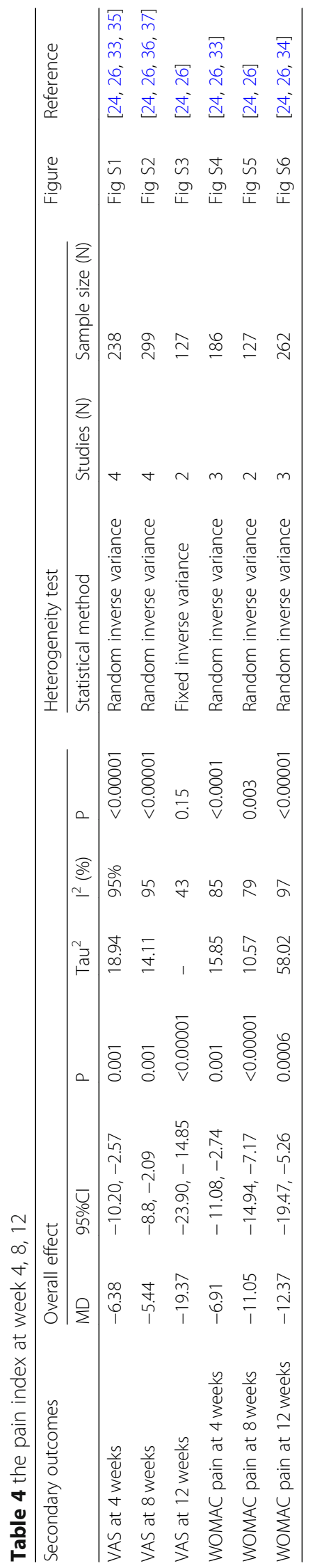




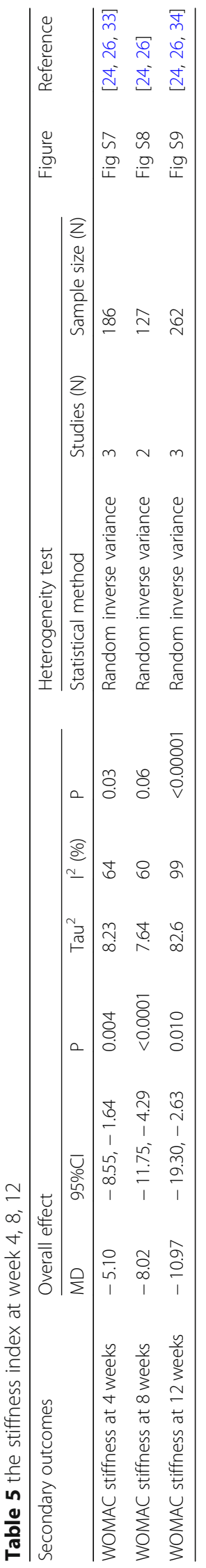




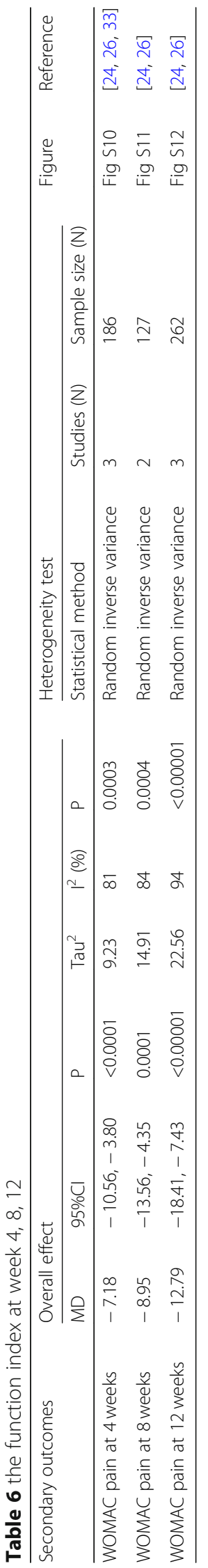




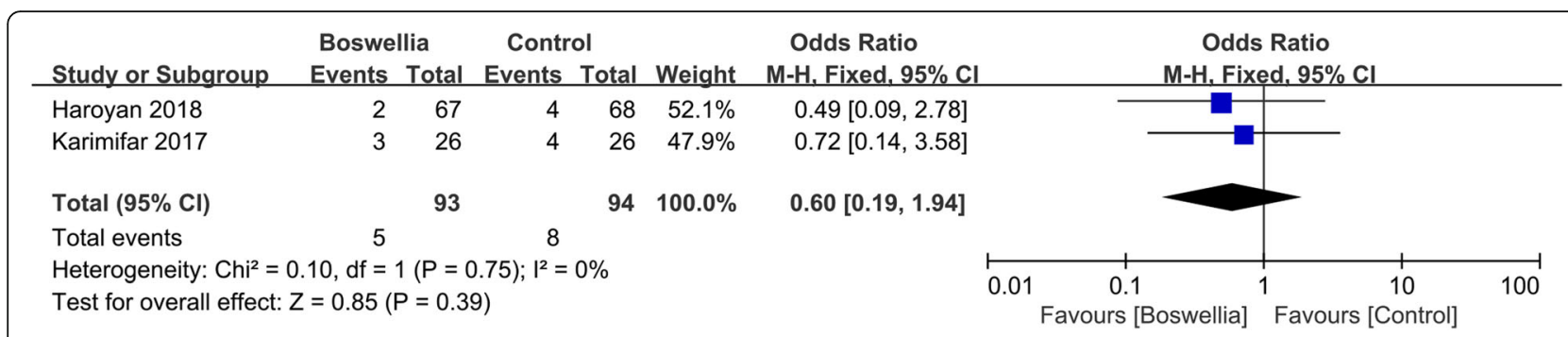

Fig. 8 Adverse events

and cases included in this study is insufficient; the heterogeneity of some outcomes is high; these all affect the accuracy of the conclusions. The heterogeneity may be related to the discrepancies in the pharmacological effects of different Boswellia preparations. This may result from the different standardization of Boswellia and its extract manufacturing process, dosage, duration of treatment, units of laboratory tests and races of the selected patients or other places. Meanwhile, the recommended duration and dosage of treatment should also be interpreted with caution because the pain, stiffness and function index between week 1 and week 4 and the dosage of Boswellia and its extract outside $100-250 \mathrm{mg}$ were not reported. Additionaly, since the quality of the RCTs is generally medium to low, all results should be interpreted more cautiously. Last but not least, further rigorously designed studies with high quality are needed to confirm the effectiveness and safety of Boswellia and its extract preparations for patients with OA.

\section{Conclusion}

This systematic review and meta-analysis showed that Boswellia and its extract may be a novel drug for patient with OA. Based on current evidence, the recommended duration and dosage of treatment with Boswellia and its extract is at least $100-250 \mathrm{mg} 4$ weeks. However, current $\mathrm{RCTs}$ have limitations, including the missing information of pain, stiffness and function index between week 1 and week 4 and small sample sizes. Meanwhile, since the quality of the RCTs is generally medium to low, we should formulate the conclusion more cautiously. More double-blind, large sample size RCTs of Boswellia and its extract for OA that reported pain, stiffness and function index before 4 weeks and the dosage of Boswellia and its extract outside 100-250 $\mathrm{mg}$ are needed in the future to confirm or modify the result of this work.

\section{Supplementary information}

Supplementary information accompanies this paper at https://doi.org/10. 1186/s12906-020-02985-6.

Additional file 1.

Additional file 2 .

\section{Additional file 3.}

Additional file 4.

Additional file 5.

Additional file 6.

Additional file 7.

Additional file 8.

Additional file 9.

Additional file 10.

Additional file 11.

Additional file 12.

\section{Abbreviations}

OA: Osteoarthritis; NSAIDs: Non-steroidal anti-inflammatory drugs; MMP: Matrix metalloproteinase; RCT: Randomized controlled trials; AE: Adverse events

\section{Acknowledgments}

Not applicable.

\section{Authors' contributions}

$G Y, W X, L Z, K Y$ are responsible for the study concept and design. GY, LZ, KY are responsible for the literature searching; $G Y, W X, T Z, L Z, K Y$ and $J L$ are responsible for data analysis and interpretation; GY, WX, TZ, LZ, KY drafted the paper; GY and JL supervised the study; all authors participated in the analysis and interpretation of data and approved the final paper. GY and WX should be considered joint first author. GY and JL should be considered cocorresponding authors.

\section{Funding}

This research did not receive any specific grant from funding agencies in the public, commercial, or not-for-profit sectors.

Availability of data and materials

All data generated or analyzed during this study are included in this published article and its supplementary information files.

Ethics approval and consent to participate Not applicable.

Consent for publication

Not applicable.

\section{Competing interests}

The authors declare that they have no competing interests.

\section{Author details}

${ }^{1}$ The Department of Orthopaedics, People's Hospital of Ningxiang City, Ningxiang 410600, Hunan Province, China. ${ }^{2}$ Graduate College, Guilin Medical University, Guilin, Guangxi Province, China. ${ }^{3}$ Department of Rheumatology, Affiliated Hospital of Guilin Medical University, Guilin, Guangxi Province, China. ${ }^{4}$ Graduate College, University of South China, Hengyang, Hunan Province, China. ${ }^{5}$ Department of Cardiology, The First Affiliated Hospital of University of South China, Hengyang, Hunan Province, China. ${ }^{6}$ Graduate 
College, Chinese Academy of Medical Sciences \& Peking Union Medical College, Beijing, China. ${ }^{7}$ Hunan University of Chinese Medicine, Changsha 410208, Hunan Province, China.

Received: 3 February 2020 Accepted: 9 June 2020

Published online: 17 July 2020

\section{References}

1. Felson DT. An update on the pathogenesis and epidemiology of osteoarthritis. Radiol Clin N Am. 2004:42:1-9.

2. Felson DT, Lawrence RC, Dieppe PA, et al. Osteoarthritis: new insights. Part 1: the disease and its risk factors. Ann Intern Med. 2000;133:635-46.

3. Karen WB, Javaid K, Arden N, et al. Regular review: medical management of osteoarthritis. BMJ. 2000;321:936-40.

4. Beringer $A$, Miossec P. Systemic effects of IL-17 in inflammatory arthritis. Nat Rev Rheumatol. 2019;15(8):491-501. https://doi.org/10.1038/s41584-019-0243-5.

5. Hochberg MC, Altman RD, Brandt KD, et al. Guidelines for the medical management of osteoarthritis. Part II. Osteoarthritis of the knee. American College of Rheumatology. Arthritis Rheum. 1995;38:1541-6. https://doi.org/ 10.1002/art.1780381104.

6. Anonymous. Recommendations for the medical management of osteoarthritis of the hip and knee: 2000 update: American College of Rheumatology Subcommittee on Osteoarthritis Guidelines. Arthritis Rheum. 2000; 43: 1905-1915.

7. Pendleton A, Arden N, Dougados M, et al. EULAR recommendations for the management of osteoarthritis: report of task force standing committee for international clinical studies including therapeutic trials (ESCISIT). Ann Rheum Dis. 2000;59:936-44. https://doi.org/10.1136/ard.59.12.936.

8. Singh $\mathrm{G}$. Recent considerations in nonsteroidal anti-inflammatory drug gastropathy. Am J Med. 1998;105:31S-8S.

9. Griffin MR. Epidemiology of nonsteroidal anti-inflammatory drug associated gastrointestinal injury. Am J Med. 1998;104:23S-9S.

10. Wright JM. Double-edged sword of COX-2 selective NSAIDs. CMAJ. 2002; 167:1131-7.

11. Singh GB, Atal CK. Pharmacology of an extract of salai guggal ex-Boswellia serrata, a new non-steroidal anti-inflammatory agent. Agents Actions. 1986; 18:407-41.

12. Ethan B, Heather B, Theresa DH, Ivo F, Sadaf H, Jens $H$, David S, Catherine U. Boswellia. An evidence-based systematic review by the natural standard research collaboration. J Herbal Pharmacother. 2004;4:63-83.

13. Safayhi H, Mack T, Sabieraj J, et al. Boswellic acids: novel, specific, nonredox inhibitors of 5-lipoxygenase. J Pharmacol Exp Ther. 1992;26:1143-6.

14. Sailer ER, Subramanian LR, Rall B, et al. Acetyl-11-keto- $\beta$-boswellic acid (AKBA): structure requirements or binding and 5-lipoxygenase inhibitory activity. Br J Pharmacol. 1996;117:615-8.

15. Kimmatkar N, Thawani V, Hingorani L, et al. Efficacy and tolerability of Boswellia serrata extract in treatment of osteoarthritis of knee: a randomized double blind placebo controlled trial. Phytomedicine. 2003;10:3-7.

16. Perera PK, Perera M, Kumarasinghe N. Effect of Sri Lankan traditional medicine and Ayurveda on Sandhigata Vata (osteoarthritis of knee joint). Ayu. 2014;35:411-5. https://doi.org/10.4103/0974-8520.159007.

17. Shah MR, Mehta CS, Shukla VD, et al. A Clinical study of Matra Vasti and an ayurvedic indigenous compound drug in the management of Sandhigatavata (Osteoarthritis). Ayu. 2010;31:210-7. https://doi.org/10.4103/ 0974-8520.72399.

18. Gupta PK, Samarakoon SM, Chandola HM, et al. Clinical evaluation of Boswellia serrata (Shallaki) resin in the management of Sandhivata (osteoarthritis). Ayu. 2011;32:478-82. https://doi.org/10.4103/0974-8520.96119.

19. Roy S, Khanna S, Shah H, et al. Human genome screen to identify the genetic basis of the anti-inflammatory effects of Boswellia in microvascular endothelial cells. DNA Cell Biol. 2005;24:244-55. https://doi.org/10.1089/dna.2005.24.244.

20. Syrovets T, Buchele B, Krauss C, et al. Acetyl-boswellic acids inhibit lipopolysaccharide mediated TNF-alpha induction in monocytes by direct interaction with IkappaB kinases. J Immunol. 2005;174:498-506.

21. Roy S, Khanna S, Krishnaraju AV, et al. Regulation of vascular responses to inflammation: inducible matrix metalloproteinase-3 expression in human microvascular endothelial cells is sensitive to anti-inflammatory Boswellia. Antioxid Redox Signal. 2006;3:653-60

22. Sengupta K, Golakoti T, Marasetti A, et al. 30\% 3-0-acetyl-11-keto- $\beta$ boswellic acid inhibits TNFa production and blocks MAPK/NFkB activation in lipopolysaccharide induced THP-1 human monocytes. J Food Lipids. 2009;16:325-44

23. Krishnaraju AV, Sundararaju D, Vamsikrishna U, et al. Safety and toxicological evaluation of Aflapin: a novel Boswellia-derived anti-inflammatory product. Toxicol Mech Methods. 2010;20:556-63.

24. Sengupta K, Krishnaraju AV, Vishal AA, et al. Comparative efficacy and tolerability of 5-Loxin ${ }^{\oplus}$ and Aflapin ${ }^{\circledast}$ against osteoarthritis of the knee: a double blind, randomized, placebo controlled clinical study. Int J Med Sci. 2010;7:366-77.

25. Lalithakumari K, Krishnaraju AV, Sengupta K, et al. Safety and toxicological evaluation of a novel, standardized 3-O-acetyl-11-keto- $\beta$-boswellic acid (AKBA)-enriched Boswellia serrata extract (5-Loxin). Toxicol Mech Methods. 2006;16:199-226. https://doi.org/10.1080/15376520600620232.

26. Sengupta K, Krishnaraju AV, Satish AR, et al. A double blind, randomized, placebo controlled study of the efficacy and safety of 5-Loxin for treatment of osteoarthritis of the knee. Arthritis Res Ther. 2008;10:R85.

27. Gayathri B, Manjula N, Vinaykumar KS, et al. Pure compound from Boswellia serrata extract exhibits anti-inflammatory property in human PBMCs and mouse macrophages through inhibition of TNFa, IL-1 $\beta, \mathrm{NO}$ and MAP kinases. Int Immunopharmacol. 2007;7:473-82.

28. Liu X, Machado GC, Eyles JP, Ravi V, Hunter DJ. Dietary supplements for treating osteoarthritis: a systematic review and meta-analysis. $\mathrm{Br} J$ Sports Med. 2018:52:167-75. https://doi.org/10.1136/bjsports-2016-097333.

29. Cameron M, Chrubasik S. Oral herbal therapies for treating osteoarthritis. Cochrane Database Syst Rev. 2014;22:CD002947. https://doi.org/10.1002/ 14651858.CD002947.pub2.

30. Moher D, Liberati A, Tetzlaff J, Altman DG, The PRISMA group. Preferred Reporting Items for Systematic Reviews and Meta-Analyses: The PRISMA Statement. BMJ. 2009;339:b2535. https://doi.org/10.1136/ bmj.b2535.

31. Deeks JJ, Higgins JP, Altman DG. Chapter 16: special topics in statistics. In: Higgins JP, Green S, editors. Cochrane handbook for systematic reviews of interventions. UK: The Cochrane Collaboration; 2011.

32. Deeks JJ, Higgins JP, Altman DG. Chapter 8: assessing risk of bias in included studies. In: Higgins JP Green S, editors. Cochrane handbook or systematic reviews of interventions version 5.1.0. UK: The Cochrane Collaboration; 2011

33. Vishal AA, Mishra A, Raychaudhuri SP. A double blind, randomized, placebo controlled clinical study evaluates the early efficacy of aflapin in subjects with osteoarthritis of knee. Int J Med Sci. 2011:8:615-22.

34. Haroyan A, Mukuchyan V, Mkrtchyan N, et al. Efficacy and safety of curcumin and its combination with boswellic acid in osteoarthritis: a comparative, randomized, double-blind, placebo-controlled study. BMC Complement Altern Med. 2018;18:7. https://doi.org/10.1186/ s12906-017-2062-z.

35. Karimifar M, Soltani R, Hajhashemi V, et al. Evaluation of the effect of Elaeagnus angustifolia alone and combined with Boswellia thurifera compared with ibuprofen in patients with knee osteoarthritis: a randomized double-blind controlled clinical trial. Clin Rheumatol. 2017:36:1849-53. https://doi.org/10.1007/s10067-017-3603-z.

36. Notarnicola A, Maccagnano G, Moretti L, et al. Methylsulfonylmethane and boswellic acids versus glucosamine sulfate in the treatment of knee arthritis: randomized trial. Int J Immunopathol Pharmacol. 2016:29:140-6. https://doi. org/10.1177/0394632015622215.

37. Notarnicola A, Tafuri S, Fusaro L, et al. The "MESACA" study: methylsulfonylmethane and boswellic acids in the treatment of gonarthrosis. Adv Ther. 2011;28:894-906. https://doi.org/10.1007/s12325-011-0068-3.

38. Chopra A, Lavin P, Patwardhan B, Chitre D. A 32-week randomized, placebocontrolled clinical evaluation of RA-11, an Ayurvedic drug, on osteoarthritis of the knees. J Clin Rheumatol. 2004:10(5):236-45.

39. Chopra A, Saluja M, Tillu G, Sarmukkaddam S, Venugopalan A, Narsimulu G, Handa R, Sumantran V, Raut A, Bichile L, Joshi K, Patwardhan B. Ayurvedic medicine offers a good alternative to glucosamine and celecoxib in the treatment of symptomatic knee osteoarthritis: a randomized, double-blind, controlled equivalence drug trial. Rheumatology (Oxford). 2013;52(8):1408-17. https://doi.org/10.1093/ rheumatology/kes414 Epub 2013 Jan 30.

40. Belcaro G, Dugall M, Luzzi R, Ledda A, Pellegrini L, Hu S, Ippolito E. Management of osteoarthritis (OA) with the pharma-standard supplement FlexiQule (Boswellia): a 12-week registry. Minerva Gastroenterol Dietol. 2015; 22 [Epub ahead of print]. 
41. Bolognesi G, Belcaro G, Feragalli B, Cornelli U, Cotellese R, Hu S, Dugall M. Movardol ${ }^{\oplus}$ (N-acetylglucosamine, Boswellia serrata, ginger) supplementation in the management of knee osteoarthritis: preliminary results from a 6-month registry study. Eur Rev Med Pharmacol Sci. 2016;20(24):5198-204

42. Badria FA, et al. Boswellia-Curcumin Preparation for Treating Knee Osteoarthritis: A Clinical Evaluation. Alter and Comple Therap. 2002;12:341-8.

43. Loke Y, Price D, Herxheimer A. Chapter 14: adverse effects. In: JPT H, Green $\mathrm{S}$, editors. Cochrane handbook for systematic reviews of interventions. Chapter 14. Chichester: Wiley; 2011.

44. Ioannidis JP, Evans SJ, Gøtzsche PC, et al. Better reporting of harms in randomized trials: an extension of the CONSORT statement. Ann Intern Med. 2004;141:781-8.

45. Deeks JJ, Higgins JP, Altman DG. Chapter 9: Analyzing data and undertaking meta-analyses. In: Higgins JP, Green S, editors. Cochrane handbook for systematic reviews of interventions. UK: The Cochrane Collaboration; 2011.

\section{Publisher's Note}

Springer Nature remains neutral with regard to jurisdictional claims in published maps and institutional affiliations.

Ready to submit your research? Choose BMC and benefit from:

- fast, convenient online submission

- thorough peer review by experienced researchers in your field

- rapid publication on acceptance

- support for research data, including large and complex data types

- gold Open Access which fosters wider collaboration and increased citations

- maximum visibility for your research: over $100 \mathrm{M}$ website views per year

At $\mathrm{BMC}$, research is always in progress.

Learn more biomedcentral.com/submissions 